\title{
Effectiveness of Manual Vacuum Aspiration PLUS in The Treatment of Incomplete Abortion in the First Trimester of Pregnency
}

\author{
Kamrun Naher', Abul Hossain ${ }^{2}$, Amina Rahman ${ }^{3}$, Shelina Pervin ${ }^{4}$, Mohammad Rezaul Karim ${ }^{5}$ Umme Jannatul Ferdous ${ }^{6}$
}

\begin{abstract}
:
Background \& objective: With the advent of Misoprostol, medical termination of pregnancy in the first trimester has become a popular choice. But its indiscriminate use with inadequate doses more often results in incomplete abortion. Manual Vacuum Aspiration PLUS (MVA-PLUS) is claimed to be an effective treatment modality for incomplete abortion. The present study was intended to evaluate the effectiveness of MVA-PLUS in the treatment of incomplete abortion.

Methods: This cross-sectional study was conducted in Sherpur District Hospital, Sherpur, Bangladesh. Pregnant women of 8-12 weeks of gestation receiving tablet Misoprostol by untrained personnel and presented to us with incomplete abortion were included in the study. Patients with complete abortion, ectopic pregnancy, signs of pelvic infection or sepsis were excluded from our study. MVA-Plus was done by paracervical block, analgesia and/or mild sedation and verbal reassurance. Successful outcome was defined in terms of complete evacuation of the product of conceptus.
\end{abstract}

Result: The study subjects were generally young, married with low educational background. Treatment with MVA-PLUS showed that majority (98\%) of the patients have had complete evacuation with minimum duration of hospital stay (1-2 days) in majority of the cases ( $82 \%)$. The need for blood transfusion varied from 1-2 units $(76 \%)$ to more than 5 units $(4 \%)$. No major complications were noted.

Conclusion: Manual Vacuum Aspiration PLUS (MVA-PLUS) is highly effective in the treatment of incomplete abortion in the first trimester of pregnency with no side effect and minimum stay in the hospital.

Key words: MVA-PLUS, Misoprostol, incomplete abortion, effectiveness etc.

\section{INTRODUCTION:}

Five decades ago in 1967, the world health assembly identified unsafe abortion as a serious public health problem for women in many countries. ${ }^{1,2}$ Following this, safe motherhood conference was held in Nairobi, Kenya in February 1987. The first report of abortion-related deaths was published in 1989, which showed that at least 11,500 abortion related-deaths occurred annually due to unsafe abortion. Only then the extent of this public health problem was understood. Unsafe

\section{Authors' information:}

${ }^{1}$ Dr. Kamrun Naher, Assistant Professor (Obstetrics \& Gynaecology), Mymensingh Medical College, Mymensingh

${ }^{2}$ Dr. Abul Hossain, Associate Professor (Obstetrics \& Gynaecology), Mymensingh Medical College, Mymensingh

${ }^{3}$ Dr. Amina Rahman, Junior Consultant (Anestheology) Sherpur District Hospital, Sherpur

${ }^{4}$ Dr. Shelina Pervin, Junior consultant (Obstetrics \& Gynaecology), Mughda Medical College \& Hospital, Mughda, Dhaka

${ }^{5}$ Dr. Mohammad Rezaul Karim, Medical Officer (Anaethesia), Sherpur District Hospital, Sherpur

${ }^{6}$ Dr. Umme Jannatul Ferdous, Medical Officer, Sherpur District Hospital, Sherpur

Correspondence: Dr. Kamrun Naher, Cell Phone: +8801711477143, Email: kamrunnahernargis@gmail.com 
abortion contributes substantially to the global burden of maternal mortality and morbidity. ${ }^{2,3}$

Mortality owing to unsafe abortions was calculated to be $13 \%$ of all maternal deaths. At the Nairobi conference, Halfdan Mahler, the then DirectorGeneral of WHO, highlighted the importance of access to family planning services and essential obstetric care for avoiding maternal deaths because of illegal abortion from unwanted pregnancy. ${ }^{4,5}$ Unplanned pregnancy opts for the abortion method which is unsafe in most of the cases. Most of the unsafe abortion occur in developing countries in low-income groups and the unmet need for contraception is high. Rate of unsafe abortion \& maternal mortality is still high in Bangladesh. ${ }^{6}$ Emergency treatment of complications from incomplete $\&$ unsafe abortion is an effective intervention to reduce maternal mortality. MVAPLUS is a recent addition to the management of incomplete abortion in N'Djamena Hospitals, Chad. ${ }^{7,8}$

Emergency treatment of incomplete abortion by MVA-Plus coupled with adequate follow-up and contraception saves life of patients. WHO recommends MVA-Plus as a preferred method for uterine evacuation of incomplete abortion in early pregnancy. ${ }^{9}$ There is no known contraindication of MVA-Plus for treatment of incomplete abortion for uterine size upto 12 weeks of last menstrual period (LMP) or first trimester abortion. MVA-Plus is a safe $\&$ effective clinical procedure. Studies report effectiveness rate of MVA-Plus to be in excess of $98 \%$ with extremely lower complications rate. Other studies demonstrate that MVA-Plus achieves greater safety than sharp curettage. ${ }^{10,11}$ MVA-Plus is done by paracervical block, analgesia and or mild sedation and verbal reassurance. This method is sufficient for women's comfort during the procedure..$^{9,10}$ The present study was intended to evaluate the effectiveness of MVA-PLUS in the treatment of incomplete abortionon in patients attending at the Department of Obstetrics and Gynecology, Sherpur District Hospital, Dhaka, Bangladesh who took inadequate doses of misoprostol by untrained personnel.

\section{METHODS:}

This cross-sectional study was conducted in Sherpur District Hospital, Sherpur, Bangladesh. Pregnant women of 8-12 weeks of gestation receiving tablet Misoprostol by untrained personnel and presented to us with incomplete abortion were included in the study. Patients with complete abortion, ectopic pregnancy, signs of pelvic infection or sepsis were excluded from the study. Baseline characteristics studied were age, educational status, marital status, occupational status, gravida, while treatment related variables were blood transfusion needed, hospital stay and outcome of MVA-Plus. MVA-Plus was performed by paracervical block, analgesia and/or mild sedation and verbal reassurance. Successful outcome was defined in terms of complete evacuation of the product of conceptus.

\section{RESULTS:}

Age distribution shows that the respondents were predominantly in their $2^{\text {nd }}$ decades (20-30 years old) of life (72\%). Forty percent of the respondents were primary level educated, $30 \%$ SSC and $19 \%$ HSC level educated. Majority (96\%) was married and only a few were unmarried $(2 \%)$, widow $(1 \%)$ and divorced ( $1 \%)$. More than two-thirds $(68 \%)$ of the respondents were housewife, followed by service-holders (30\%) and student (2\%). In terms of religion, Muslims formed the majority (98\%) (Table I). Most $(84 \%)$ of the respondents was multigravida $\left(2^{\text {nd }}-3^{\text {rd }}\right)$ and $14 \%$ were grand multigravida ( $4^{\text {th }}$ gravida or more) (Fig. 1). Over $75 \%$ of the patients needed $1-2$ units, $20 \% 3-4$ units and $4 \%$ more than 4 units of blood transfusion (Table II). Majority (82\%) of the respondents stayed in the hospital for 1-2 days, $16 \% 3$ days \& only $2 \% \quad 4-5$ days (Table III). One-fifth of the respondents took barrier methods of contraception and another $20 \%$ took injectable contraception. The rest $60 \%$ took oral contraception (OCP) (Table IV). Most (98\%) of the respondents had complete evacuation (Table $\mathrm{V}$ ). 


\begin{tabular}{|c|c|c|}
\hline Demographic characteristics & Frequency & Percentage \\
\hline \multicolumn{3}{|l|}{ Age } \\
\hline$<20$ & 8 & 8.0 \\
\hline $20-25$ & 36 & 36.0 \\
\hline $25-30$ & 36 & 36.0 \\
\hline $30-35$ & 16 & 16.0 \\
\hline $35-40$ & 4 & 4.0 \\
\hline \multicolumn{3}{|l|}{ Education } \\
\hline Illiterate & 10 & 10.0 \\
\hline Primary & 40 & 40.0 \\
\hline SSC & 30 & 30.0 \\
\hline HSC & 19 & 19.0 \\
\hline Graduate & 1 & 1.0 \\
\hline \multicolumn{3}{|l|}{ Marital Status } \\
\hline Unmarried & 2 & 2.0 \\
\hline Married & 96 & 96.0 \\
\hline Divorced & 1 & 1.0 \\
\hline Widow & 1 & 1.0 \\
\hline \multicolumn{3}{|l|}{ Occupation } \\
\hline Student & 2 & 2.0 \\
\hline Housewife & 68 & 68.0 \\
\hline Service & 30 & 30.0 \\
\hline \multicolumn{3}{|l|}{ Religious } \\
\hline Muslim & 98 & 98.0 \\
\hline Hinduism & 2 & 2.0 \\
\hline
\end{tabular}

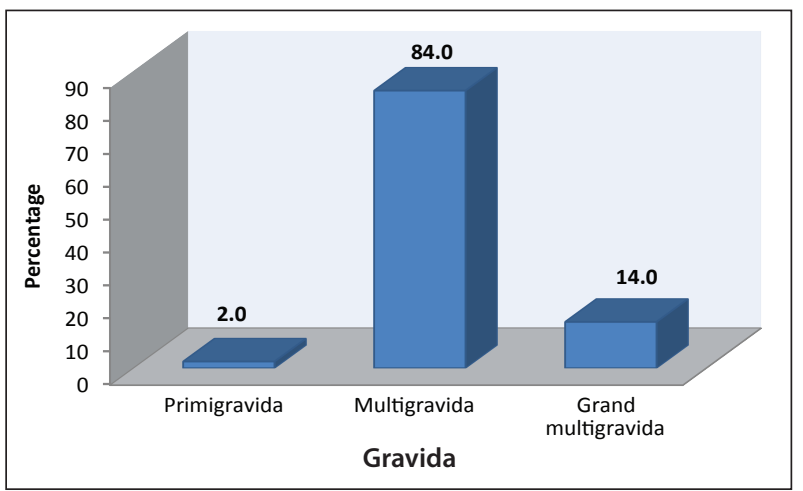

Fig. 1: Distribution of patients by their gravida $(n=100)$

TABLE II. Distribution of patients by need of blood transfusion ( $n=50)$

$\begin{array}{lcc}\text { Blood transfusion (units) } & \text { Frequency } & \text { Percentage } \\ 1-2 & 38 & 76.0 \\ 3-4 & 10 & 20.0 \\ >4 & 2 & 4.0\end{array}$

TABLE III. Distribution of patients by their hospital stay:

\begin{tabular}{|lcc}
\hline Hospital stay (days) & Frequency & Percentage \\
$1-2$ & 82 & 82.0 \\
$2-3$ & 16 & 16.0 \\
$4-5$ & 2 & 2.0
\end{tabular}

TABLE IV. Distribution of patients by their contraception history:

$\begin{array}{lcc}\text { Contraception } & \text { Frequency } & \text { Percentage } \\ \text { OCP } & 60 & 60.0 \\ \text { Barrier methods } & 20 & 20.0 \\ \text { Injectable } & 20 & 20.0\end{array}$

TABLE V. Effectiveness of MVA-Plus and Paracervical block: $(n=100)$

$\begin{array}{lcc}\text { Effectiveness of MVA-Plus } & \text { Frequency } & \text { Percentage } \\ \text { \& paracervical block } & 98 & 98.0 \\ \text { Complete evacuation } & 02 & 02.0\end{array}$

\section{DISCUSSION:}

Induction of first-trimester pregnancy (8-12 weeks) with misoprostol by untrained personels was not found effective. These patients when admitted in the Sherpur District Hospital, were treated by Gynecologist with MVA-PLUS \& paracervical block. We also provided post-abortion follow up care in our hospital which decreased maternal morbidity. Multiple studies showed that treatment of incomplete abortion by MVA-PLUS is safe and effective and is a useful tool in low resource settings for women with incomplete abortion and a uterus size of less than 12 weeks. ${ }^{11-15}$ MVA-PLUS has advantages over standard surgical curettage for both the patients and the health care providers in reducing hospital cost, waiting time and hospital stay. ${ }^{13}$ Koontz and associates ${ }^{16}$ in a study in EI Salvader on 154 women showed that MVA-PLUS reduces cost by $13 \%$ and shortens hospital stay by $28 \% .{ }^{16}$ MVA-PLUS procedure has a high level of patient satisfaction as evidenced by more than $90 \%$ of women who received it recommended the same to their fellows needing treatment for incomplete abortion. ${ }^{9}$

Successful outcome of treatment with MVA PLUS and paracervical block was observed to be commendably high (98\%). A recent Vietnamese study examined 210 first trimester MVA abortion \& provided extensive follow up. Complete evacuation was very high with no serious complications, such as infection or heavy bleeding. ${ }^{9}$ When misoprostol is provided by doctors or midwives in adequate doses, complete abortion occurs in most of the cases (94-99\%), as evidenced by a study in 
Uganda. ${ }^{17}$ Most of the patients admitted in our hospital received in adequate doses of misoprostol by untrained health care providers \& that might be the reason of unwantedly high incomplete abortion. Ipas, a Women's Sexual \& Reproductive Rights Organization, facilitated training on MVA-Plus for evacuation of uterus upto 12 weeks to doctors and senior staff nurses in Bangladesh. The personnel trained on MVA-PLUS found it safe and effective technique for uterine evacuation. Its low-cost, simplicity and potability has made it an especially valuable reproductive health technology. More than 30 years of clinical and programmatic research in over 100 countries has shown vacuum aspiration for uterine evacuation to be safer and more effective than sharp curettage. The present study, like other past studies, showed appreciably high success rate of MVA procedure with extremely low complication rates.

\section{CONCLUSION:}

The study showed that MVA-PLUS is effective in the treatment of incomplete abortion. Misoprostol with adequate doses can be used when MVA-PLUS is not possible or available. Special training of health workers on MVA-PLUS is, however, needed for its beneficial application to the patients.

\section{REFERENCES:}

1. Twentieth World Health Assembly Resolution 20.14: Health Aspects of Family Planning. Geneva, Switzerland: World Health Organization; 1967.

2. Look PFAV, Cottingham J. The World Health Organization's Safe Abortion Guidance Document. Am J Public Health 2013;103(4):593-96. doi: 10.2105/AJPH.2012. 301204.

3. Royston E, Armstrong S. Preventing Maternal Deaths. Geneva, Switzerland: World Health Organization; 1989.

4. Mahler $\mathrm{H}$. The safe motherhood initiative: a call to action. Lancet 1987;1(8534):668-70.

5. Look PFAV, Cottingham J. The World Health Organization's Safe Abortion Guidance Document. Am J Public Health 2013;103(4):593-96. doi: 10.2105/AJPH.2012. 301204.

6. CIA World Factbook. Cited:05/06/2018 10:48 AM; Available at: https://www.indexmundi.com/bangladesh/ maternal_mortality_rate.html
7. Foumsou L, Kainba P, Mahamat P. Interest of manual vacuum aspiration in the management of incomplete abortion for the first trimester at N'Djamena Mother and Child Hospital. Annales de la société Guinnééne de Gynecology-Obstétrique 2015;24(10):7-12.

8. Madoue GB, Daniel D, Tchari A, Chene M, Salah KM, Brahim Z, Naîm C, Steve N. Comparison of manual vacuum aspiration and misoprostol in the management of incomplete abortion. South Sudan Medical Journal 2016;9(4):76-78.

9. World Health Organization (WHO). 2003. Safe abortion: Technical and policy guidance for health systems. Geneva, WHO.

10. Frankel, Nina \& Marian Abernathy, eds. 2007. Performing uterine evacuation with the Ipas MVA Plus $®$ aspirator and Ipas Easy Grip ${ }^{\circ}$ cannulae: Instructional booklet. $2^{\text {nd }}$ edition. Chapel Hill, NC, Ipas. P. 7,8.

11. Greenslade FC, Leonard AH, Benson J, Winkler J, Henderson VL. 1993. Manual vacuum aspiration: A summary of clinical and programmatic experience worldwide. Carrboro, NC, Ipas. Baird, Traci L. and Susan K. Flinn. 2001. Manual vacuum aspiration: Expanding women's access to safe abortion services. Chapel Hill, NC, Ipas.

12. Etuk SJ, Ebong IF, Okonofua FE. Knowledge, attitude and practice of private medical practitioners in Calabar towards post abortion care. Afr J Reprod Health 2003;7 (3):55-64.

13. Dah $T$, Akiode $A$, Awah $P$, Fetters $T$, Okoh M, Ujah I, Oji E. Introducing Misoprostol for the treatment of incomplete abortion in Nigeria. Afr J Reprod Health 2011;15 (4):42-50

14. Rasch V. Unsafe abortion and postabortion care- an overview. Acta Obstet Gynecol Scand 2011;90:692-700.

15. Renfrew MJ, McFadden A, Bastos MH, Campbell J, Channon $A A$, Cheung NF, et al. Midwifery and quality care: findings from a new evidence-informed framework for maternal \& newborn care. Lancet 2014;384:1129-45.

16. Koontz SL, Molina de Perez O, Leon K, Foster-Rosales A. Treating incomplete abortion in El Salvador: cost savings with manual vacuum aspiration. Contraception 2003;68(5):345-51.

17. Vlassoff M, Mugisha F, Sundaram A, Bankole A, Singh S, Amanya L, Kiggundu C, Mirembe F. The health system cost of post abortion care in Uganda. Health Policy Plan 2014;29:56-66. 